\title{
Penentuan Data Anthropometri untuk Perancangan Ulang Produk dengan Meninjau Interaksi Pengguna \\ (Studi Kasus Perancangan Ulang Kursi Roda ISO 7176 untuk Anak-Anak Tuna Daksa)
}

\author{
Determination of Anthropometry Data for Product Redesigning \\ by Considering User Interaction \\ (Case Study Redesigning Wheel Chair ISO 7176 \\ for Orthopedically Handicapped Children)
}

\section{Andrijanto, Boy Parulian Hutapea}

Program Studi Teknik Industri, Universitas Kristen Maranatha Bandung

E-mail: andrijanto@eng.maranatha.edu, boyparulianhutapea@gmail.com

\begin{abstract}
Abstrak
Perancangan produk dilakukan untuk menjawab kebutuhan pengguna, sehingga pengguna dapat berinteraksi dengan baik ketika menggunakannya. Akan tetapi ada produk terstandarisasi yang tidak dapat berfungsi secara optimal karena tidak sesuai dengan kondisi pengguna sehingga perlu dilakukan perancangan ulang. Penelitian ini bertujuan menentukan data antropometri untuk perancangan ulang dengan memperhatikan interaksi pengguna dengan produk. Interaksi antara pengguna $(U)$ dan produk $(P)$ akan menghasilkan data antropometri (AT) yang dibutuhkan dalam perancangan. Diharapkan dengan penentuan data antropometri yang tepat produk dapat diperbaiki dan dapat digunakan dengan aman dan nyaman

Studi kasus perancangan ulang kursi roda ISO 7176 yang digunakan oleh anak-anak tuna daksa pada sekolah luar biasa di Bandung. Interaksi siswa dengan kursi roda dianalisis untuk menentukan data-data antropometri. Duapuluh siswa pengguna kursi roda dengan rentang usia 6-12 tahun diukur tubuhnya. Uji normal dan keseragaman data yang dilakukan terhadap data hasil pengukuran menunjukkan hasil yang layak untuk dipakai sebagai acuan. Pembagian persentil dilakukan untuk memberikan patokan pada penentuan dimensi kursi roda. Sepuluh data anthropometri anak-anak tunadaksa dengan rentang usia 6-12 telah disusun dan dapat digunakan sebagai acuan untuk perancangan kursi roda.

Kata kunci: ergonomi, antropometri, perancangan ulang produk
\end{abstract}

\begin{abstract}
Product is designed to answer the customer needs; that product should interact with the user well while being used. However standardized product sometimes cannot interact well with user because it does not comply with user condition physically. To answer that problem, the product must be redesigned to match the physical condition of user. This research purpose is determining anthropometry data (AT) for product redesigned by considering user (U) interaction with the product $(P)$. The anthropometry data is expected can be used to modify product parts for complying the user physical condition then the product can be use safely and comfortably.

Case study is used to describe steps of determination anthropometry data. A wheelchair ISO 7176 is redesigned product $(P)$ in purpose to comply the physical condition of user. Users $(U)$ are children with physical disability. They are using wheelchair ISO 7176 while studying in the special school. Twenty students with range of age between 6-12 years old will be analyzed and measured to obtain anthropometry data while interacting with wheelchair. Raw data will be normality tested and uniformity tested. Further the percentile distribution is done for benchmarking parts dimension of wheelchair. Ten data anthropometry of children with physical disability have been obtained and can be used as benchmark for redesigning wheelchair.
\end{abstract}

Keywords: ergonomic, anthropometry, product redesigned 


\section{Pendahuluan}

\subsection{Latar Belakang}

Perancangan ulang suatu produk dilakukan untuk menyesuaikan dimensi produk dengan pengguna. Tujuannya adalah membuat produk tersebut dapat digunakan dengan aman dan nyaman. Berbeda dengan perancangan suatu produk baru, dimensi dapat mengacu pada suatu standar tertentu, seperti ISO untuk standar produk yang diakui secara internasional, atau JIS untuk standar produk yang digunakan oleh negara Jepang. Perancangan ulang suatu produk belum memiliki patokan dimensi baru yang akan memperbaiki dimensi aktualnya. Penelitian ini bertujuan mengembangkan suatu metode yang dapat digunakan untuk menentukan dimensi baru suatu produk rancang ulang dengan memperhatikan bagian-bagian produk yang memiliki interaksi dengan penggunanya. Dimensi tersebut akan menyesuaikan dengan data antropometri dari pengguna. Dalam hal ini data antropometri memiliki keterkaitan erat dengan perancangan suatu produk (Zakaria, N., 2014, Gupta, D., 2014, Gill, 2015)

Sebuah studi kasus perancangan ulang kursi roda ISO 7176 akan dilakukan untuk menjelaskan cara penentuan data antropometri dengan mempertimbangkan interaksi produk dengan pengguna. Pengguna kursi roda adalah anak-anak tuna daksa pada sebuah sekolah luar biasa bagian D (SLBD) di kota Bandung. Anak-anak tuna daksa yang berada di sekolah tersebut sebagian besar akibat bawaan dari lahir atau penyakit, khususnya polio. Ada 20 anak-anak penyandang cacat yang menggunakan kursi roda, dengan rentang usia antara 6-12 tahun menjalani pendidikan di sekolah tersebut. Mereka menggunaka kursi roda ISO 7176 untuk melakukan aktivitas di sekolah tersebut.

\subsection{Batasan dan Asumsi}

Data anthrometri akan dikumpulkan dengan cara mengukur tubuh 20 anak-anak. Uji normal dan keseragaman akan dilakukan terhadap data. Uji kecukupan tidak dapat dilakukan karena pengukuran dilakukan terhadap seluruh populasi (sampel jenuh). Tingkat ketelitian yang digunakan adalah 5\% dan tingkat kepercayaan 95\%. Data anthropometri akan dibagi menjadi 3 persentil. 5\%, $50 \%$, dan $95 \%$.

\section{Landasan Teori}

\subsection{Ergonomi}

Berdasarkan International Ergonomics Association (IEA), kata "Ergonomi" berasal dari bahasa yunani Ergon (kerja) dan Nomos (hukum alam). Ergonomi adalah keilmuan yang berorientasi pada sistem yang terus dikembangkan terhadap aspek-aspek manusia. Mendukung pendekatan secara holistic yang mempertimbangkan physical, cognitive, sosial, organisasi, lingkungan, dan faktorfaktor lain yang terkait dengannya.

Ergonomi pada umumnya diterapkan pada aktivitas rancang bangun (desain) ataupun rancang ulang (re-desain). Hal ini dapat meliputi perangkat keras seperti misalnya perkakas kerja (tools), bangku kerja (benches), platform, kursi, pegangan alat kerja (workholders), sistem pengendali (controls), alat peraga (displays), jalan / lorong (acces ways), pintu (doors), jendela (windows), dan lain-lain. Ergonomi juga digunakan untuk rancang bangun lingkungan kerja (working environment), desain pekerjaan, desain perangkat lunak, dan yang tidak kalah pentingnya adalah desain dan evaluasi produk. Di samping itu ergonomi juga memberikan peranan penting dalam meningkatkan faktor keselamatan dan kesehatan kerja. (Nurmianto, 1996).

\subsection{Antropometri}

Antropometri adalah ilmu pengetahuan yang berkaitan dengan pengukuran tubuh manusia. Antropometri merupakan sekumpulan data numerik yang berhubungan dengan karakter fisik tubuh manusia yang meliputi ukuran, bentuk, dan kekuatan yang diterapkan pada suatu perancangan (Stevenson, 1989; Nurmianto, 1996). 


\subsubsection{Antropometri Statis}

Antropometri statis merupakan ukuran tubuh manusia yang diperoleh saat manusia berada dalam keadaan diam (statis) pada suatu kondisi tertentu (Ahlstorm et. al., 2003). Misal ukuran tubuh manusia pada saat duduk yang akan digunakan untuk perancangan kursi makan dan meja makan. Perbedaan pada suatu hasil pengukuran dibandingkan dengan pengukuran yang lain dapat terjadi karena hal-hal berikut: data acak/random pada suatu populasi, perbedaan jenis kelamin, perbedaan suku bangsa, perbedaan usia, perbedaan jenis pekerjaan, perbedaan jenis pakaian yang sedang dikenakan, adanya faktor kehamilan pada wanita, dan adanya cacat tubuh secara fisik.

\subsubsection{Antropometri Dinamis}

Antropometri dinamis merupakan ukuran tubuh manusia yang didapat dari berbagai macam posisi tubuh yang sedang bergerak (Ahlstorm et. al., 2003). Misal pada saat keluar-masuk sebuah pintu yang dikondisikan pada saat berpapasan dengan orang lain akan menggunakan beberapa patokan ukuran tubuh manusia untuk mempertimbangkan segala kemungkinan ukuran pintu yang sesuai dengan kondisi yang diinginkan.Terdapat tiga kelas pengukuran antropometri dinamis yaitu:

- Pengukuran tingkat ketrampilan mempertimbangkan keadaan mekanis suatu aktivitas

- Pengukuran jangkauan ruang ideal yang dibutuhkan saat bekerja. Sebagai contoh jangkauan efektif kaki dan tangan saat melakukan kerja pada saat berdiri dan duduk.

- Pengukuran variabilitas kerja dilakukan dengan mempertimbangkan aktivitas-aktivitas yang dilakukan dalam sebuah mekanisme kerja.

\subsection{Perancangan Ergonomi}

Perancangan (yang) ergonomi adalah pemahaman dalam menerapkan prinsip-prinsip ergonomis ke dalam perancangan sistem, yang dapat berupa perangkat kerja, peralatan, atau seluruh dari lingkungan kerja (Rebelo et. al., 2016). Postur manusia ketika melakukan kerja/beraktivitas di office menjadi pertimbangan dalam perancangan produk yang ergonomis, yaitu: berdiri, duduk, menjangkau, dan berpindah (Openshaw et. al., 2006). Antropometri sangat penting dalam penentuan dimensi suatu produk rancangan untuk membuat sebuah produk dapat digunakan dengan nyaman dan aman.

\section{Metodologi}

Perancangan sebuah produk yang ergonomis akan menggambarkan interaksi manusia ketika menggunakan produk tersebut dengan aman dan nyaman. Penentuan karakter dari produk rancangan, karakter pengguna, dan karakter pekerjaan akan menentukan data antropometri yang digunakan sebagai acuan (Gupta, 2014). Dalam industri tekstil data antropometri disesuaikan dengan produk baju menggunakan fit mapping (Daanen et. al., 2007). Fit mapping mencocokan data antropometri dengan pergerakan tubuh manusia sehingga produk baju akan nyaman dikenakan. Perancangan ulang produk tentunya akan menyesuaikan interaksi postur (A) dari pengguna $(\mathrm{U})$ dengan komponen $(\mathrm{K})$ dari produk $(\mathrm{P})$ untuk menentukan data antropometri (AT) yang digunakan dalam analisis perancangan.

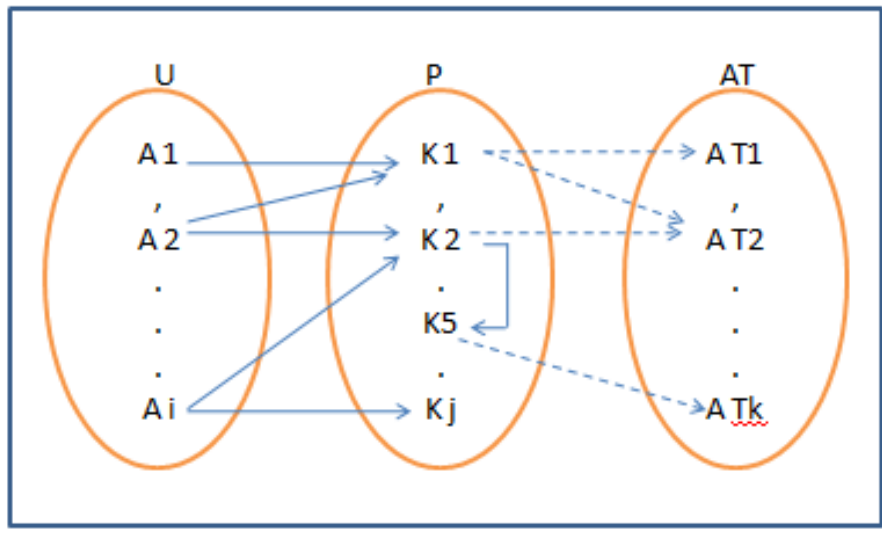

Gambar 1. Diagram Interaksi Pengguna (U) dengan Produk (P) 
Dari gambar 3.1 dapat dijelaskan, misal pengguna (U) memiliki postur-postur (Ai) ketika menggunakan produk $\{\mathrm{A} 1, \mathrm{~A} 2, \mathrm{~A} 3, \ldots, \mathrm{Ai}\} \in \mathrm{U}$, dimana produk $(\mathrm{P})$ memiliki komponenkomponen $(\mathrm{Kj})$ yang berinteraksi dengan pengguna $\{\mathrm{K} 1, \mathrm{~K} 2, \mathrm{~K} 3, \ldots, \mathrm{Kj}\} \in \mathrm{P}$, maka antropometri (AT) adalah dimensi-dimensi tubuh pengguna (ATk) yang dibutuhkan untuk perancangan ulang \{ AT1, AT2, AT3, ..., ATk $\} \in$ AT. Relasi tersebut merupakan irisan antara postur pengguna dengan komponen produk ketika beraktivitas, sehingga dapat dituliskan sebagai berikut: $\mathrm{U} \cap \mathrm{P}=\mathrm{AT}$

Sebuah komponen produk dapat berhubungan dengan suatu postur secara tidak langsung, seperti contoh pada gambar 3.1 komponen 5 secara tidak langsung berhubungan dengan postur A2 lewat komponen 3. Komponen yang berhubungan tidak langsung dengan suatu postur akan dianalisis untuk mengetahui apakah komponen tersebut memerlukan data antropometri tertentu yang akan memperbaharui dimensi aktualnya.

\subsection{Pengguna (U) dan Produk (P)}

Pada tahap pertama perlu dijelaskan pengguna dari produk dan postur mereka ketika beraktivitas menggunkan produk. Setelah itu dijelaskan produk yang akan dirancang ulang. Produk tersebut dibagi menjadi beberapa komponen dimana komponen-komponen tersebut memiliki keterkaitan secara langsung atau tidak langsung dengan pengguna.

\subsubsection{Pengguna (U)}

Pengguna dalam studi kasus ini adalah anak-anak tuna daksa di sebuah sekolah luar biasa bagian D. Menurut kamus kedokteran online tunadaksa adalah orang yang mengalami gangguan gerak disebabkan oleh kelainan neuro-muskuler dan struktur tulang yang bersifat bawaan, penyakit, atau akibat kecelakaan. Pada SLB-D anak-anak tuna daksa melakukan aktivitas menggunakan kursi roda. Mereka duduk dikursi dan melakukan aktivitas-aktivitas dengan postur ketika: duduk, berpindah tempat, dan menjangkau. Aktivitas dengan postur berdiri jarang dilakukan, hanya untuk ke toilet dan berpindah ke kursi mobil ketika pulang. Dari postur mereka maka bagian kursi roda yang berinteraksi dengan mereka adalah:

- Postur ketika duduk (A1) berinteraksi dengan alas tempat duduk, sandaran punggung, dan pijakan kaki

- Postur ketika berpindah tempat (A2) berinteraksi dengan roda belakang/kemudi

- Postur ketika menjangkau (A3) berinteraksi dengan sandaran tangan dan sandaran punggung untuk bertumpu

- Postur ketika berdiri (A4) akan berinteraksi dengan sandaran tangan untuk bertumpu Maka U memiliki 4 postur ketika beraktivitas, $\{$ A1, A2, A3, A4 $\} \in U$

\subsubsection{Produk (P)}

Produk yang akan dirancang ulang adalah kursi roda untuk anak-anak tuna daksa akan menggunakan kursi roda orang dewasa (ISO 7176) sebagai produk yang akan disesuaikan dimensinya dengan antropometri anak tunadakasa. Berdasarkan interaksi anak-anak dengan kursi roda maka kursi roda tersebut akan dibagi menjadi 6 komponen yang memiliki keterkaitan dengan dimensi tubuh anak-anak. Kursi akan dibagi menjadi alas tempat duduk dan sandaran punggung. Roda belakang memiliki hubungan tidak langsung dengan roda depan sebagai penyeimbang, sehingga roda depan juga dimasukkan dalam bagian kursi roda yang akan dianalisis. Komponenkomponen tersebut dapat dilihat pada gambar 3.1., yaitu:

- $\quad$ Alas tempat duduk (K1)

- $\quad$ Sandaran punggung (K2)

- Sandaran tangan (K3)

- $\quad$ Pijakan kaki (K4)

- Roda belakang/kemudi (K5)

- $\quad$ Roda depan (K6)

Berdasarkan interaksi aktivitas dengan komponen didapat 6 komponen yang akan dianalisis dimensinya, $\{\mathrm{K} 1, \mathrm{~K} 2, \mathrm{~K} 3, \mathrm{~K} 4, \mathrm{~K} 5, \mathrm{~K} 6\} \in \mathrm{P}$. Dimensi dari rangka kursi roda akan disesuaikan dengan dimensi tubuh pengguna yang baru sesuai dengan interaksinya dengan komponen- 
komponen tersebut. Gambar 3.2 menunjukkan dimensi aktual dari rangka kursi roda yang akan disesuaikan.
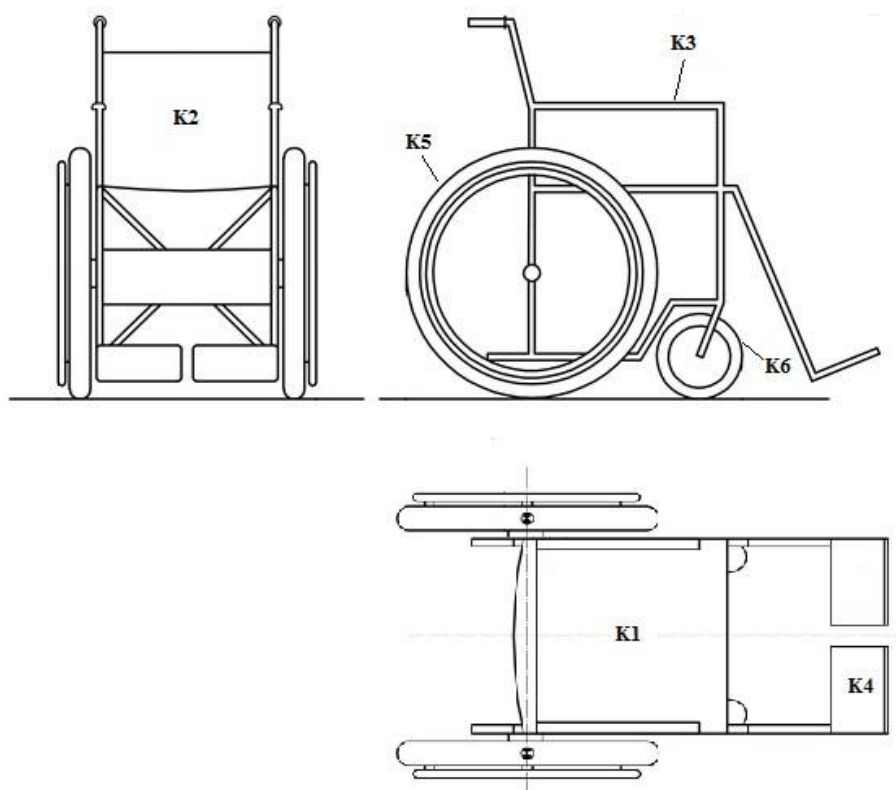

Gambar 2. Komponen Rancang Ulang Kursi Roda ISO 7176

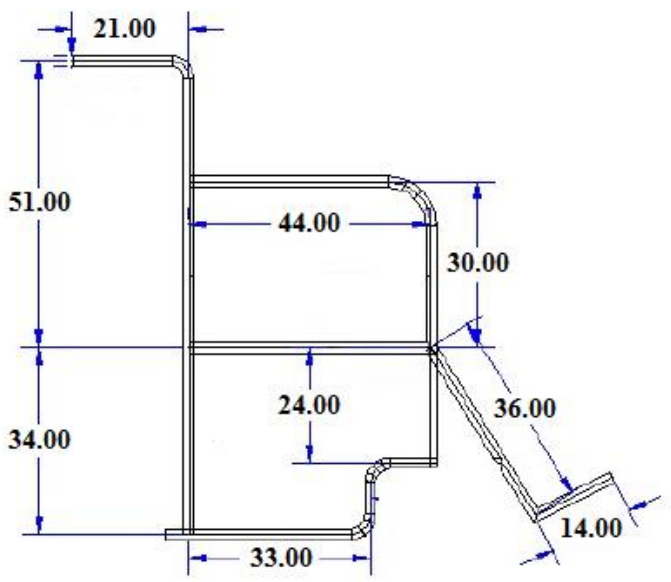

Gambar 3. Dimensi Rangka Kursi Roda ISO 7176

\subsection{Penentuan Antropometri (AT)}

Penentuan data antropometri yang dibutuhkan dalam perancangan ulang akan dilakukan dengan merelasikan komponen-komponen (K) kursi roda ketika digunakan dengan anggota tubuh manusia (AT) ketika melakukan aktivitas dengan postur (A).

\subsubsection{Alas Tempat Duduk (K1)}

Alas tempat duduk berupa bidang persegi yang memiliki dimensi panjang, lebar, dan ketinggian dari tanah yang harus ditentukan ketika pengguna beraktivitas duduk. Bagian tubuh pinggang kebawah akan berinteraksi langsung dengan alas tempat duduk. Maka relasi antara komponen dengan anggota tubuh adalah sebagai berikut:

- Panjang kursi akan ditentukan oleh lebar panggul (AT1)

- Lebar kursi akan ditentukan oleh jarak lipat lutut (popliteal) ke pantat (AT2)

- $\quad$ Tinggi kursi dari tanah akan ditentukan oleh tinggi lipat lutut (popliteal) (AT3) 


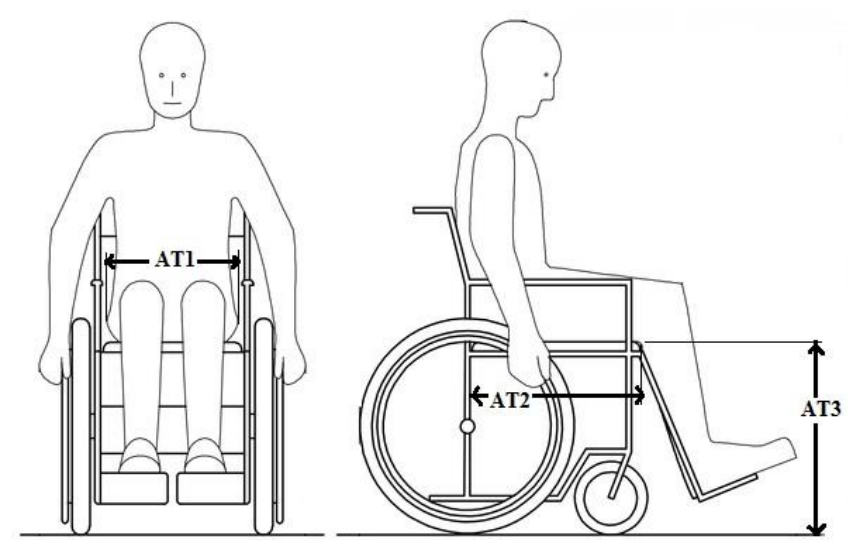

Gambar 4. Relasi Komponen K1 dengan Antropometri

\subsubsection{Sandaran Punggung (K2)}

Sandaran punggung kursi digunakan ketika pengguna menyandarkan punggungnya saat duduk di kursi. Punggung pengguna akan berinteraksi langsung dengan komponen K2. Sandaran punggung ini berupa bidang persegi yang memiliki panjang, lebar, dan ketinggian dari atas tanah, sehingga relasi antara komponen dengan anggota tubuh punggung adalah sebagai berikut:

- Panjang sandaran punggung akan ditentukan oleh lebar bahu (AT4)

- Lebar sandaran punggung dan tinggi berimpit akan ditentukan oleh tinggi bahu pada posisi duduk (AT5)

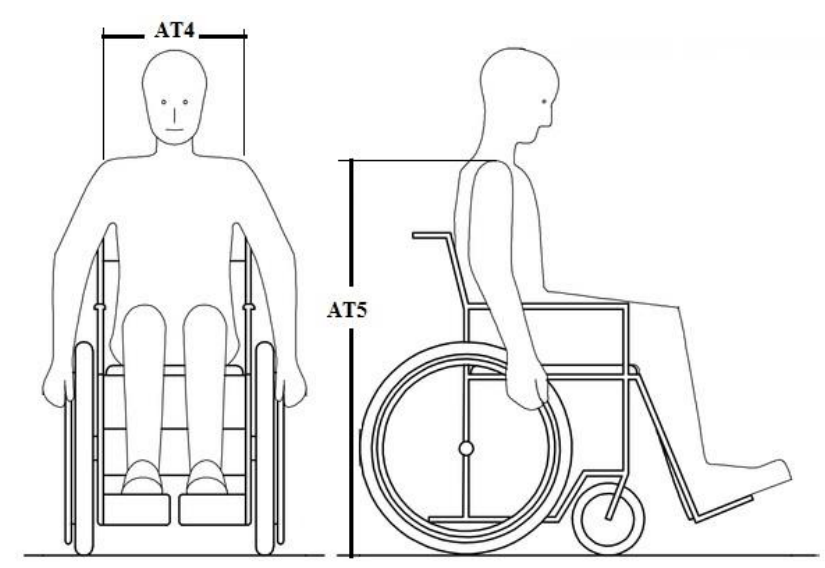

Gambar 5. Relasi Komponen K2 dengan Antropometri

\subsubsection{Sandaran Tangan (K3)}

Sandaran tangan merupakan komponen dari kursi roda yang digunakan ketika pengguna duduk santai dengan meletakkan tangan pada sandaran atau ketika bertumpu untuk berdiri atau menjaga keseimbangan ketika hendak merubah postur. Maka bagian lengan dan tangan yang berelasi dengan sandaran tangan adalah:

- Panjang sandaran tangan adalah jarak siku ke ujung jari (AT6)

- Tinggi sandaran tangan dari lantai adalah tinggi siku pada posisi duduk (AT7)

- Lebar sandaran tangan adalah lebar telapak tangan (AT8) 


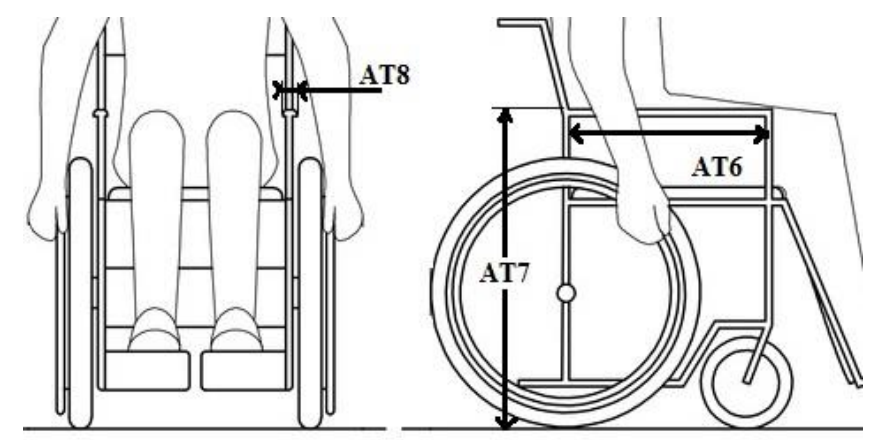

Gambar 6. Relasi Komponen K3 dengan Antropometri

\subsubsection{Pijakan Kaki (K4)}

Pijakan kaki digunakan ketika pengguna duduk di kursi roda pada keadaan diam atau ketika berpindah tempat. Untuk anak-anak tuna daksa yang lemah pada bagian kaki, pijakan kaki akan sangat membantu mereka supaya kaki tidak terjuntai ke bawah dan terseret ketika berpindah tempat. Maka bagian tungkai kaki dan telapak kaki yang berelasi dengan komponen ini adalah:

- $\quad$ Panjang pijakan kaki adalah panjang telapak kaki (AT9)

- $\quad$ Lebar pijakan kaki adalah lebar telapak kaki (AT10)

- $\quad$ Panjang penyangga pijakan kaki adalah tinggi lipat lutut (popliteal) (AT3)

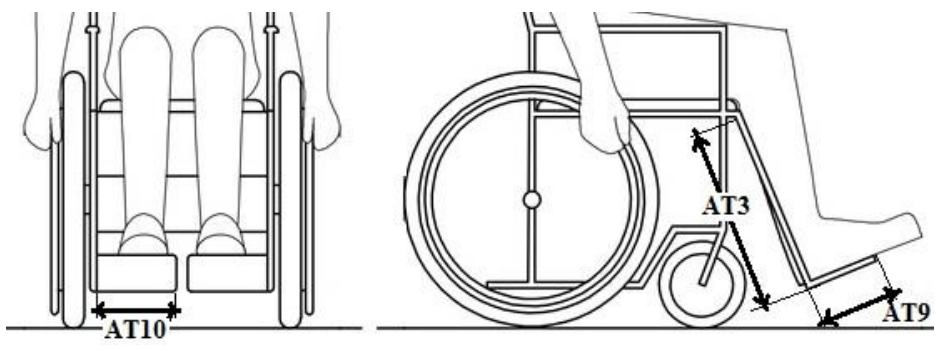

Gambar 7. Relasi Komponen K4 dengan Antropometri

\subsubsection{Roda Belakang/Kemudi (K5)}

Kursi roda memiliki kendali di roda belakang. Pengguna dapat bergerak maju/mundur atau merubah arah kursi roda dengan menggerakkan roda pengendali yang terpasang pada roda belakang. Posisi roda pengendali harus dapat dijangkau dan digenggam dengan mudah oleh pengguna sehingga pengguna dapat meyalurkan tenaganya ke roda belakang. Maka bagian lengan dan telapak tangan pengguna berelasi dengan komponen ini sebagai berikut:

- Jangkauan tangan pengguna ke roda pengendali menggunakan jarak siku ke ujung jari (AT6) Pada gambar 3.6 diasumsi jangkauan terendah pada titik $\mathrm{Y}$ merupakan jarak terjauh yang harus bisa dijangkau oleh pengguna. Sedangkan titik tertinggi $X$ adalah jarak terpendak yang bisa dijangkau oleh pengguna. Diamater roda pengendali aktual adalah $52 \mathrm{~cm}$.

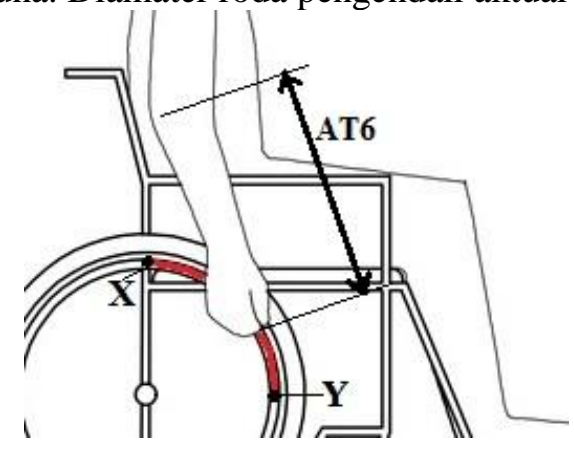

Gambar 8. Relasi Komponen K5 dengan Antropometri 
- Diameter roda belakang akan dipengaruhi dengan tinggi alas kursi. Perubahan pada ketinggian alas kursi akan menyebabkan diameter roda belakang juga akan mengecil. Hal ini dilakukan supaya posisi tertinggi roda pengendali $\mathrm{X}$ masih tetap bisa dijangkau dengan mudah dan nyaman. Diameter roda belakang aktual adalah $60 \mathrm{~cm}$.

\subsubsection{Roda Depan (K6)}

Roda depan tidak memiliki relasi langsung dengan dimensi tubuh manusia. Sebagai komponen yang berfungsi menopang tungkai kaki, komponen ini juga berfungsi menjadi penyeimbang ketika pengguna melakukan garakan berpindah tempat. Diameter roda depan akan menjaga jarak antara penopang kaki dengan lantai selalu $2 \mathrm{~cm}$. Diameter roda depan ini dipengaruhi oleh diameter dari roda belakang. Diameter roda depan aktual adalah $23 \mathrm{~cm}$.

\subsection{Relasi Pengguna, Produk dan Antropometri}

Untuk mengambarkan relasi antara produk $(\mathrm{P})$ ketika melakukan aktivitas dengan postur pengguna (U) yang membutuhkan antropometri (AT) maka dapat dibuat sebuah matriks yang dapat dilihat pada gambar 3.7 .

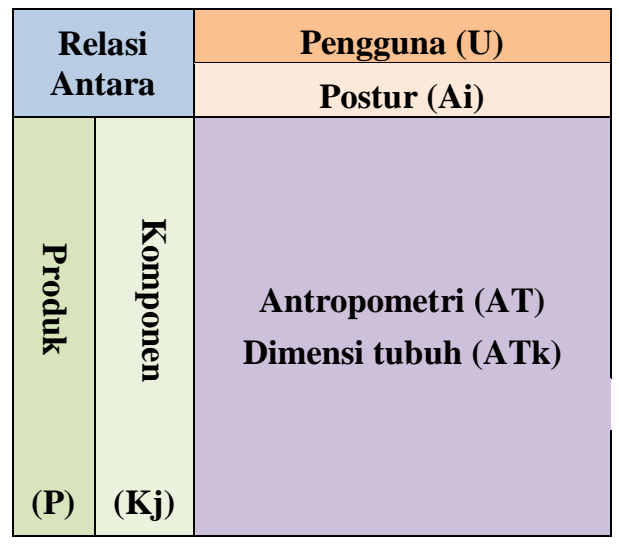

Gambar 9. Matriks Relasi U-P-AT

Maka berdasarkan studi kasus perancangan ulang kursi roda ISO 7176 yang disesuaikan dengan anak-anak tuna daksa, matriks relasi UPAT dapat digambarkan sebagai berikut:

1. Aktivitas pengguna yang membentuk beberapa postur ketika berinteraksi dengan kursi roda akan dituliskan pada baris Postur (Ai)

2. Komponen-komponen kursi roda yang berelasi dengan postur akan dituliskan pada kolom Komponen (Kj)

3. Irisan antara postur pengguna dengan komponen adalah dimensi tubuh (ATk), dituliskan pada setiap kotak Antropometri (AT).

Matriks relasi UPAT untuk perancangan ulang kursi roda ISO 7176 dapat dilihat pada gambar 3.8 


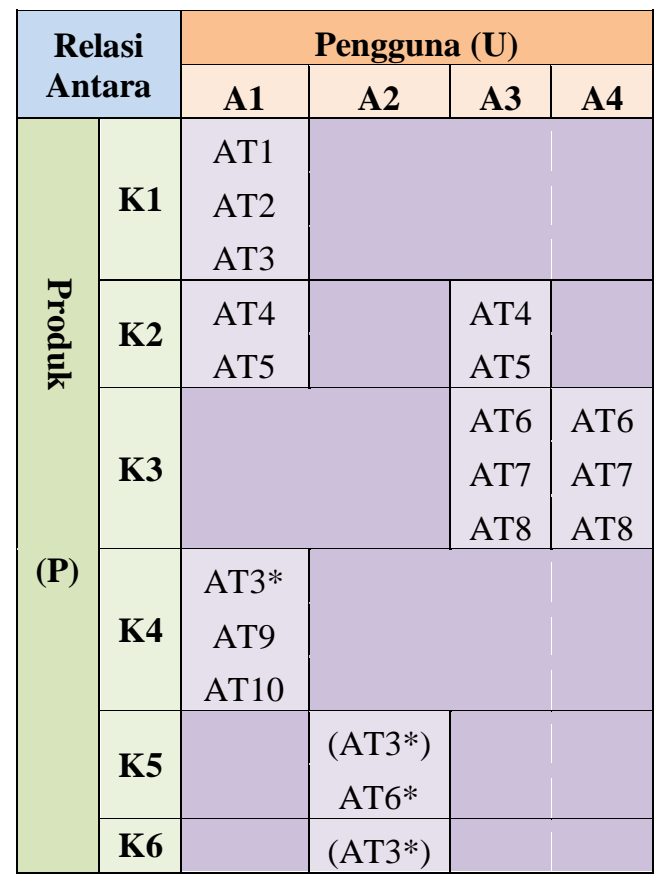

Gambar 10. Matriks UPAT Perancangan Ulang Kursi Roda ISO 7176

Pada matriks tersebut data antropometri yang digunakan berulang akan diberikan tanda *, seperti AT3* yang digunakan kembali pada komponen K4. Sedangkan data antropometri yang berelasi tidak langsung dituliskan dengan menggunakan tanda kurung ( ), seperti (AT3*) pada komponen K5 dan K6. Sedangkan AT4 di K2 dan AT6 di K3 tidak perlu diberi tanda * karena masih berelasi dengan komponen yang sama.

\subsection{Penentuan Jumlah Sampel}

Jumlah keseluruhan siswa SLB-D adalah 48 siswa dengan komposisi usia 23 siswa pada rentang usia 6 - 12 tahun dan 25 siswa pada usia diatas 12 tahun. Berdasarkan hasil pengamatan awal dan wawancara, siswa yang berusia diatas 12 tahun tidak mengalami masalah dalam menggunakan kursi roda ISO 7176. Maka pengukuran difokuskan pada siswa pada rentang usia 6-12 tahun. Jumlah sampel disesuaikan dengan jumlah sub group pada uji seragam sehingga jumlah siswa yang diukur berjumlah 20 siswa.

\section{Pengumpulan dan Pengolahan Data}

\subsection{Pengumpulan data}

Mengacu pada matriks relasi UPA maka ukuran tubuh anak-anak yang diukur dapat dilihat pada tabel 4.1 dan hasil pengukuran dapat dilihat pada tabel 4.2 
Tabel 1. Target Pengukuran Antropometri

\begin{tabular}{|l|l|}
\hline Kode & Deskripsi \\
\hline AT1 & Lebar panggul \\
\hline AT2 & Jarak lipat lutut (popliteal) ke pantat \\
\hline AT3 & Tinggi lipat lutut (popliteal) \\
\hline AT4 & Lebar bahu \\
\hline AT5 & Tinggi bahu pada posisi duduk \\
\hline AT6 & Jarak siku ke ujung jari \\
\hline AT7 & Tinggi siku pada posisi duduk \\
\hline AT8 & Lebar telapak tangan \\
\hline AT9 & Panjang telapak kaki \\
\hline AT10 & Lebar telapak kaki \\
\hline
\end{tabular}

Tabel 2. Data Mentah Pengukuran

\begin{tabular}{|c|c|c|c|c|c|c|c|c|c|c|}
\hline No. & AT1 & AT2 & AT3 & AT4 & AT5 & AT6 & AT7 & AT8 & AT9 & AT10 \\
\hline 1 & 29.7 & 28.0 & 35.6 & 25.2 & 68.7 & 28.4 & 46.6 & 7.9 & 15.4 & 6.6 \\
\hline 2 & 30.3 & 32.6 & 36.7 & 28.0 & 70.6 & 30.8 & 48.8 & 7.4 & 14.6 & 6.8 \\
\hline 3 & 32.5 & 34.6 & 39.1 & 32.0 & 81.9 & 30.1 & 57.2 & 8.2 & 16.1 & 6.7 \\
\hline 4 & 28.2 & 29.9 & 34.3 & 25.8 & 64.4 & 27.6 & 45.2 & 7.8 & 14.4 & 6.6 \\
\hline 5 & 32.4 & 30.7 & 32.4 & 27.4 & 74.3 & 28.3 & 49.5 & 8.7 & 14.8 & 6.7 \\
\hline 6 & 30.8 & 32.4 & 34.9 & 29.3 & 73.1 & 28.8 & 47.4 & 8.1 & 15.0 & 6.9 \\
\hline 7 & 31.1 & 29.5 & 34.7 & 25.7 & 62.4 & 27.9 & 45.2 & 7.9 & 15.1 & 6.8 \\
\hline 8 & 28.5 & 32.8 & 35.6 & 26.7 & 63.5 & 27.1 & 46.9 & 7.8 & 15.7 & 6.5 \\
\hline 9 & 31.9 & 32.7 & 38.9 & 28.8 & 76.8 & 27.2 & 50.4 & 8.3 & 15.4 & 7.0 \\
\hline 10 & 35.7 & 35.4 & 40.6 & 32.5 & 85.3 & 32.5 & 56.6 & 8.0 & 15.9 & 7.2 \\
\hline 11 & 29.6 & 36.3 & 38.4 & 28.6 & 81.3 & 28.6 & 55.8 & 8.4 & 16.1 & 6.8 \\
\hline 12 & 30.6 & 32.1 & 36.0 & 28.6 & 80.0 & 28.0 & 53.4 & 8.0 & 14.3 & 6.9 \\
\hline 13 & 35.4 & 37.9 & 39.1 & 34.4 & 88.5 & 33.2 & 64.0 & 8.1 & 16.2 & 7.6 \\
\hline 14 & 29.1 & 33.6 & 34.2 & 26.1 & 70.1 & 28.5 & 48.2 & 7.6 & 15.7 & 7.3 \\
\hline 15 & 28.0 & 31.3 & 35.4 & 28.2 & 72.5 & 28.5 & 46.4 & 7.5 & 15.4 & 7.1 \\
\hline 16 & 33.0 & 29.4 & 35.2 & 29.5 & 75.0 & 27.1 & 50.7 & 7.9 & 16.0 & 7.1 \\
\hline 17 & 27.2 & 30.9 & 32.1 & 24.2 & 62.1 & 26.4 & 42.1 & 7.2 & 13.6 & 6.8 \\
\hline 18 & 28.4 & 29.7 & 37.5 & 26.1 & 64.4 & 29.1 & 46.3 & 7.9 & 15.9 & 7.0 \\
\hline 19 & 30.1 & 33.2 & 37.5 & 32.6 & 83.9 & 31.3 & 58.4 & 7.4 & 16.3 & 7.3 \\
\hline 20 & 34.3 & 34.8 & 37.8 & 30.4 & 79.8 & 30.8 & 50.8 & 7.1 & 16.2 & 7.2 \\
\hline
\end{tabular}

\subsection{Pengolahan data}

Pengolahan data dilakukan dengan menguji kenormalan dan uji keseragaman data. Uji normal dengan jumlah sample $\mathrm{n}=20$, dimana $\mathrm{n} \geq 8$ maka D'Agustino's $D$ Normality Test digunakan untuk uji kenormalan (Oztuna et. al., 2006). Tahapan uji dilakukan dengan menentukan:

1. Ho: densitas populasi tidak signifikan berbeda dengan normal

$\mathrm{H}_{1}$ : densitas populasi signifikan berbeda dengan normal

2. Taraf nyata alpha $=0.05, \mathrm{n}=20$

3. Wilayah kritis: $0.2617<\mathrm{D}$ hitung $<0.2863$

Hasil uji normal untuk masing-masing nilai D dari data antropometri dapat dilihat pada tabel 4.3 
Tabel 3. Nilai D hitung Data Antropometri

\begin{tabular}{|c|c|c|}
\hline Kode & D & Status \\
\hline AT1 & 0.2817 & Normal \\
\hline AT2 & 0.2827 & Normal \\
\hline AT3 & 0.2835 & Normal \\
\hline AT4 & 0.2810 & Normal \\
\hline AT5 & 0.2804 & Normal \\
\hline AT6 & 0.2733 & Normal \\
\hline AT7 & 0.2736 & Normal \\
\hline AT8 & 0.2797 & Normal \\
\hline AT9 & 0.2766 & Normal \\
\hline AT10 & 0.2807 & Normal \\
\hline
\end{tabular}

Uji keseragaman data dilakukan dengan menghitung nilai BKB dan BKA dan masing masing data diplot pada diagram BKB-BKA untuk menunjukkan semua data seragam dan dapat digunakan sebagai data antropometri untuk perancangan ulang. Gambar 3.9 menunjukkan semua data seragam.

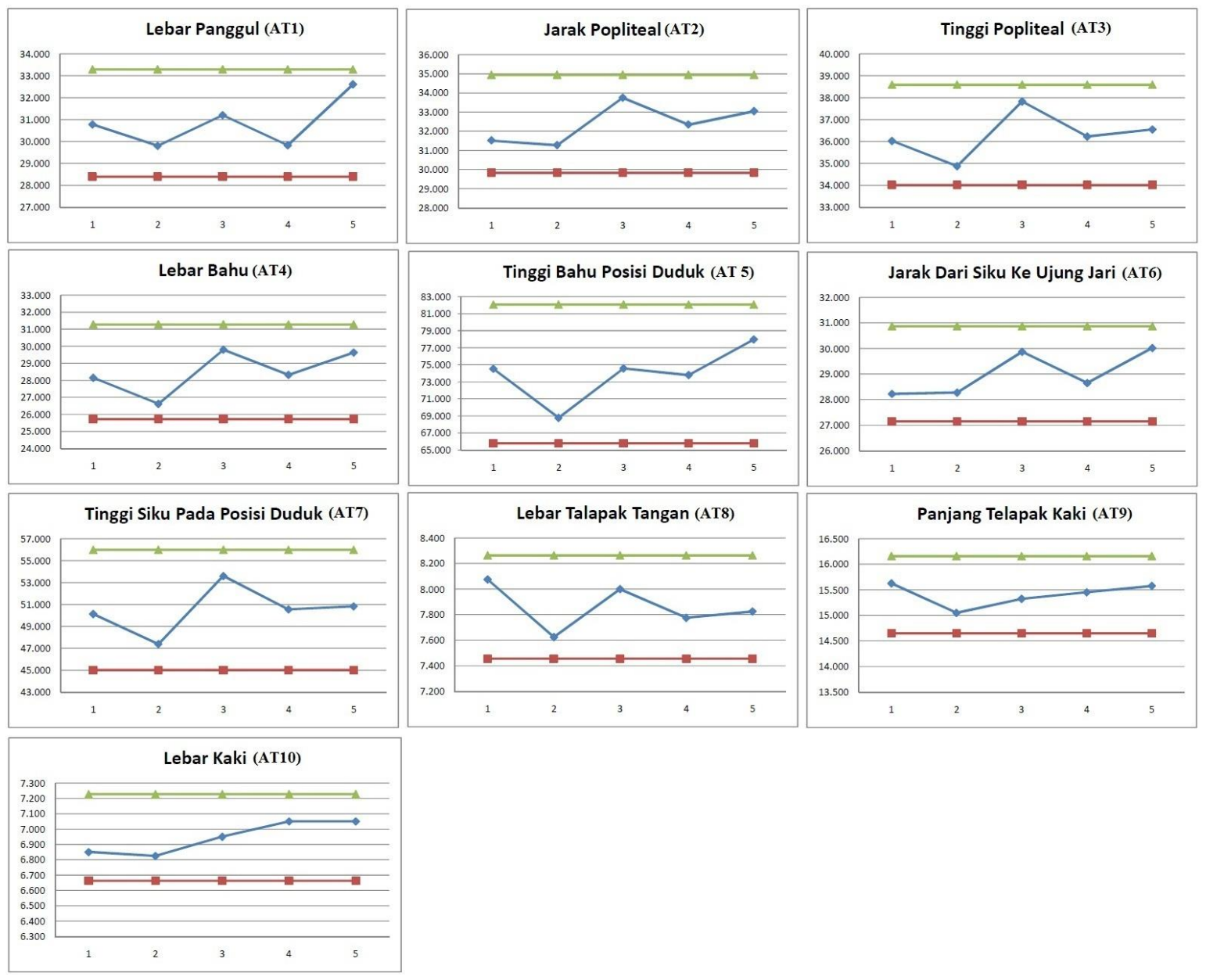

Gambar 11. Uji Keseragaman Data 


\section{Dimensi Antropometri Perancangan Ulang}

\subsection{Perhitungan persentil}

Data antropometri untuk perancangan dibagi menjadi 3 persentil: P5, P50, dan P95. Cara menghitung persentil menggunakan rumus berikut:

$\mathrm{P} 5=\mu+\sigma\left(Z_{1}\right)$

$\mathrm{P} 50=\mu$

$\mathrm{P} 95=\mu+\sigma\left(\mathrm{Z}_{2}\right)$

Hasil perhitungan persentil data antropometri untuk perancangan kursi roda ISO 7176 yang disesuaikan dengan anak-anak tuna daksa sekolah SLB D dapat dilihat pada tabel 5.1

Tabel 4. Persentil Antropometri Anak-Anak Tuna Daksa

\begin{tabular}{|l|l|r|r|r|}
\hline Kode & Deskripsi & \multicolumn{1}{c|}{ P5 } & \multicolumn{1}{c|}{ P50 } & \multicolumn{1}{c|}{ P95 } \\
\hline AT1 & Lebar panggul & 26.812 & 30.840 & 34.868 \\
\hline AT2 & Jarak lipat lutut (popliteal) ke pantat & 28.185 & 32.390 & 36.595 \\
\hline AT3 & Tinggi lipat lutut (popliteal) & 32.536 & 36.300 & 40.064 \\
\hline AT4 & Lebar bahu & 23.994 & 28.505 & 33.066 \\
\hline AT5 & Tinggi bahu pada posisi duduk & 60.540 & 73.930 & 87.320 \\
\hline AT6 & Jarak siku ke ujung jari & 25.948 & 29.010 & 32.072 \\
\hline AT7 & Tinggi siku pada posisi duduk & 41.473 & 50.495 & 59.517 \\
\hline AT8 & Lebar telapak tangan & 7.195 & 7.860 & 8.525 \\
\hline AT9 & Panjang telapak kaki & 14.164 & 15.405 & 16.646 \\
\hline AT10 & Lebar telapak kaki & 6.481 & 6.945 & 7.409 \\
\hline
\end{tabular}

\subsection{Penentuan persentil tiap komponen}

Penentuan persentil dilakukan dengan memperhatikan postur pengguna ketika berada di kursi roda.

Tabel 5.2 adalah penentuan persentil untuk setiap komponen yang telah dianalisis diatas.

Tabel 5. Penentuan Persentil Data Antropometri Terpilih

\begin{tabular}{|l|l|l|l|}
\hline K & AT & Persentil & Keterangan \\
\hline K1 & AT1 & P95 & agar dapat leluasa duduk \\
\hline & AT2 & P5 & agar popliteal tidak tertahan ujung tempat duduk \\
\hline & AT3 & P5 & agar kaki tidak menjuntai \\
\hline K2 & AT4 & P95 & agar dapat leluasa bersandar \\
\hline & AT5 & P5 & agar punggung dapat bersandar \\
\hline K3 & AT6 & P5 & agar lengan dapat bersandar \\
\hline & AT7 & P50 & agar masih dapat disesuaikan posisinya \\
\hline & AT8 & P95 & agar dapat dijadikan tumpuan \\
\hline K4 & AT3 & P5 & agar kaki dapat diletakkan pada pijakan \\
\hline & AT9 & P95 & agar kaki leluasa diletakkan pada pijakan \\
\hline & AT10 & P95 & agar kaki leluasa diletakkan pada pijakan \\
\hline K5 & AT3 & P5 & tangan masih dapat mencapai posisi tertinggi roda pengendali \\
\hline & AT6 & P5 & tangan masih dapat menjangkau posisi terendah roda pengendali \\
\hline K6 & AT3 & P5 & untuk menyesuaikan ketinggian pijakan kaki dari tanah \\
\hline
\end{tabular}




\section{Kesimpulan}

Perancangan ulang sebuah produk dengan tujuan meyesuaikan dengan aktivitas pengguna memerlukan analisis yang meninjau postur pengguna (Ai), komponen produk $(\mathrm{Kj})$, dan data antropometri (ATk) yang memiliki relasi $\mathrm{U} \cap \mathrm{P}=\mathrm{AT}$. Pada penelitian ini data antropometri yang akan digunakan pada perancangan ulang telah ditentukan dan digambarkan menggunakan matriks UPAT.

Pada studi kasus perancangan ulang kursi roda ISO 7176 didapat 4 postur, $\{$ A1, A2, A3, A4 $\} \in U$; 6 komponen, $\{\mathrm{K} 1, \mathrm{~K} 2, \mathrm{~K} 3, \mathrm{~K} 4, \mathrm{~K} 5, \mathrm{~K} 6\} \in \mathrm{P}$; dan 10 data antropometri $\{\mathrm{AT} 1, \mathrm{AT} 2$, AT3, AT4, AT5, AT6, AT7, AT8, AT9, AT10\} $\in$ AT. Sepuluh data antropometri diuji normal dan seragam, dan kemudian dibagi menjadi 3 persentil yang dapat dilihat pada tabel 5.1.

Perancangan ulang kursi roda ISO 7176 secara detail dapat dilakukan pada penelitian selanjutnya dengan menggunakan data antropometri yang telah ditentukan sebagai acuan. Penentuan persentil pada tabel 5.2 untuk masing-masing data antropometri masih dapat disesuaikan lagi kemudian pada perancangan yang dikembangkan dengan penambahan fitur-fitur atau alat bantu yang dapat menambah keamanan dan kemudahan dalam penggunaan.

\section{Daftar Pustaka}

Ahlstrom, V., Longo, K. (2003). "Human Factors Design Standard (HF-STD-001)". Atlantic City International Airport, NJ: Federal Aviation Administration William J. Hughes Technical Center.

Daanen, H.A.M., Raffeltrath, P.A. (2007). "Function, Fit, and Sizing", Chapter 6: Sizing in clothing. Developing effective sizing systems for ready-to-wear clothing, Woodhead Publishing, pp 202-218.

Gill, S. (2015), "A review of research and innovation in garment sizing, prototyping and fitting", Journal Textile Progress, 47, 1-85.

Gupta, D., Zakaria, N. (2014), "Anthropometry and The Design and Production of Apparel: an Overview", Chapter 2: Anthropometry, Apperel Sizing and Design, Woodhead Publishing, pp 3466.

Hutapea, Boy Parulian (2010), "Perancangan Kursi Roda yang Ergonomis bagi Penyandang Cacat Anak-Anak untuk Menunjang Kegiatan Belajar di SLB-D Mustang Bandung", Tugas Akhir Sarjana S1, Fakultas Teknik, Jurusan Teknik Industri, Universitas Kristen Maranatha.

Kroemer, K.H.E., Kroemer, H.B., Kroemer, K.E.-Elbert (2001), "Ergonomics How to Design for Ease and Efficiency", Prentice Hall, Inc, New Jersey 07458.

Walpole, R.E. (1980), "Introduction to Statistic", $3{ }^{\text {rd }}$ edition, Gramedia, Jakarta.

Nurmianto, E. (1996), “Ergonomi Konsep Dasar dan Aplikasinya”, Gunawidya, Jakarta.

Openshaw, S., Taylor, E.A. (2006), "Ergonomic and Design A Reference Guide”, Allsteel Inc.

Öztuna, D., Elhan, A., Tüccar, E. (2006), "Investigation of Four Different Normality Tests in Term of 1 Error Rate and Power Under Different Distribution", Turkish Journal of Medical Sciences.

Rebelo, F., Soares, M. (2016), "Ergonomics in Design: Methods and Techniques", CRC Press, Balkema.

Stevenson, M.G. (1989), "Lecture Notes On The Principies of Ergonomics", University of New South Wales, Sydney. 
PENENTUAN DATA ANTHROPOMETRI (Andrijanto, dkk.)

Zakaria, N. (2014), "Body Shape Analysis and Identification of Key Dimensions for Apparel Sizing Systems", Chapter 4: Anthropometry, Apperel Sizing and Design, Woodhead Publishing, pp 95117. 